\title{
CYCLIZATION OF TERPHENYL-BISFLUORENOL: A MECHANISTIC STUDY OF THE REGIOSELECTVITY
}

\author{
Cyril Poriel, ${ }^{*}$ Frédéric Barrière, ${ }^{*}$ Joëlle Rault-Berthelot, Damien Thirion \\ Univ Rennes, CNRS, ISCR - UMR 6226, F-35000 Rennes, France
}

\section{Introduction}

For the last thirty years of research in material science, spirobifluorene-based compounds have been extensively studied for applications in organic electronics and especially in organic lightemitting diodes (OLED). ${ }^{[1-3]}$ The incorporation of spiro linkages in small molecular units is nowadays a powerful molecular technique to design efficient and stable organic semiconductors: fluorophores for OLEDs, ${ }^{[3-8]}$ high-triplet host materials for phosphorescent OLEDs, ${ }^{[2,9-12]}$ thermally activated delayed fluorescence hosts, ${ }^{[13-15]}$ and electron-donor ${ }^{[16-18]}$ or non-fullerene acceptors ${ }^{[19-22]}$ for solar cells. The spirobifluorene fragment combines the physical advantages of an orthogonal spiro configuration (high thermal and morphological stability) and the appealing properties of the fluorene unit (e.g. high quantum yield, facile and versatile chemical functionalization). ${ }^{[23]}$ However, organic electronics is not the only application which has benefited from spirobifluorene-based compounds. One can cite for example heterogeneous and homogeneous catalysis (e.g. epoxidation, cyclopropanation...), ${ }^{[24-}$ ${ }^{29]}$ coordination polymers, ${ }^{[30]}$ or surfaces modification. ${ }^{[31]}$

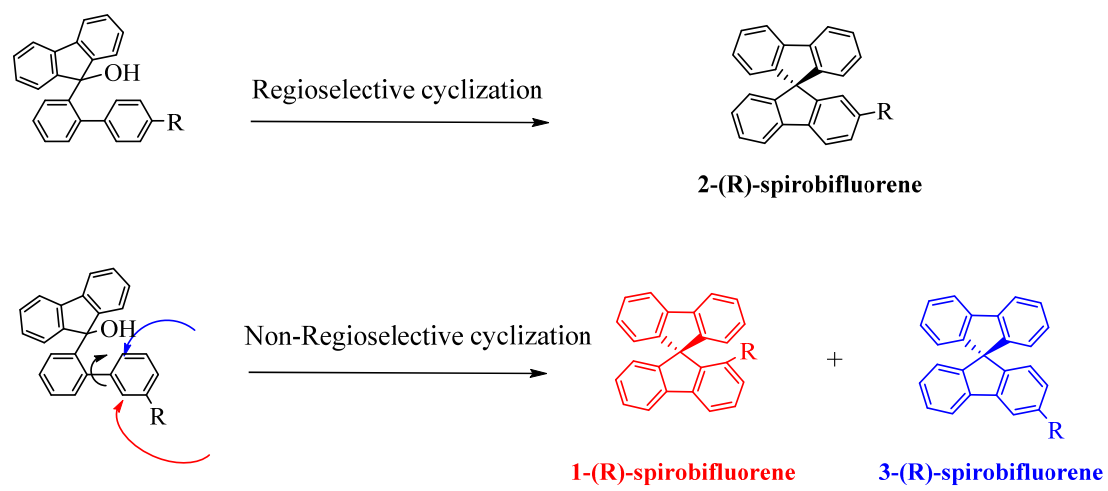

Scheme 1: Examples of intramolecular cyclization of fluoren-9-ol derivatives.

From a synthetic point of view, generating spiro-configured compounds ${ }^{[32]}$ and especially differently substituted spirobifluorenes is usually performed through intramolecular electrophilic cyclization of a fluoren-9-ol in the presence of a Lewis or a Brønsted acid (Scheme 1). ${ }^{[3,33-36]}$ If the pendant phenyl ring of the biphenyl core is substituted at its para position the intramolecular cyclization step leads to a single product, i.e. 2-substituted-spirobifluorene being hence regioselective (Scheme 1-top). However, if the pendant phenyl unit is substituted at its meta position, the electrophilic attack may occur on two different positions leading to the formation of two regioisomers (1- and 3-substituted SBF) being hence non-regioselective. This feature is due to a rotation around the biphenyl bond during the cyclization process (Scheme 1bottom) and has been previously observed notably by Lee and coworkers. ${ }^{[3]}$ Although this synthetic approach is very interesting to synthesize differently substituted spirobifluorenes, it remains to date almost absent from the literature. This absence is due to the difficulty to direct the regioselectivity of the reaction towards one single isomer. For the last ten years, our group has worked on different ways to favour such intramolecular cyclization reactions used to generate molecules with a spiro carbon linkage. These works have led to new generations of 
fused spirobifluorenes namely dispiro[fluorene-9,6'-indeno[1,2-b]fluorene-12',9"-fluorene] or DSF-IF type 2 isomers and dispiro[fluorene-9,6'-indeno[2,1-a]fluorene-12',9"-fluorene] or DSF-IF type 3 isomers (Scheme 2), which have shown promising performance when incorporated as host for phosphors in phosphorescent OLEDs or as fluorophore in $\operatorname{OLEDs}^{[4,36 \text {, }}$ ${ }^{38]}$ and even recently as hole transporting materials in perovskite solar cells. ${ }^{[18]}$ These molecules possess either the dihydroindeno[1,2-b]fluorenyl core (type $\mathbf{2}$ isomers) or the dihydroindeno[2,1-a]fluorenyl core (type 3 isomers), widely introduced in many organic semiconductors. ${ }^{[36]}$

The synthetic approach towards regioisomers $\mathbf{2}$ and $\mathbf{3}$ involves, in the last step, the intramolecular bicyclization of a bisfluorenol substituted terphenyl 1, Scheme 2, and leads to the formation of the two previously mentioned positional isomers. As these positional isomers can be separated by column chromatography, this versatile reaction has been used to produce a palette of fluorophores.${ }^{[39,40]}$ In this work, as a development to our preliminary note, ${ }^{[41]}$ we wish to report on the mechanism of this bicyclization reaction and particularly on the origin of the surprising regioselectivity observed. Through a combined experimental and theoretical study, we report herein on the rational ways of favouring the formation of one of the two possible positional isomers. As dihydroindenofluorene positional isomers are nowadays widely used building units in organic electronics, ${ }^{[1,42-44]}$ (and their antiaromatic counterparts as well ${ }^{[45]}$ ) this work allows to better understand one of their synthetic access described in the last years.

\section{Results and Discussion}

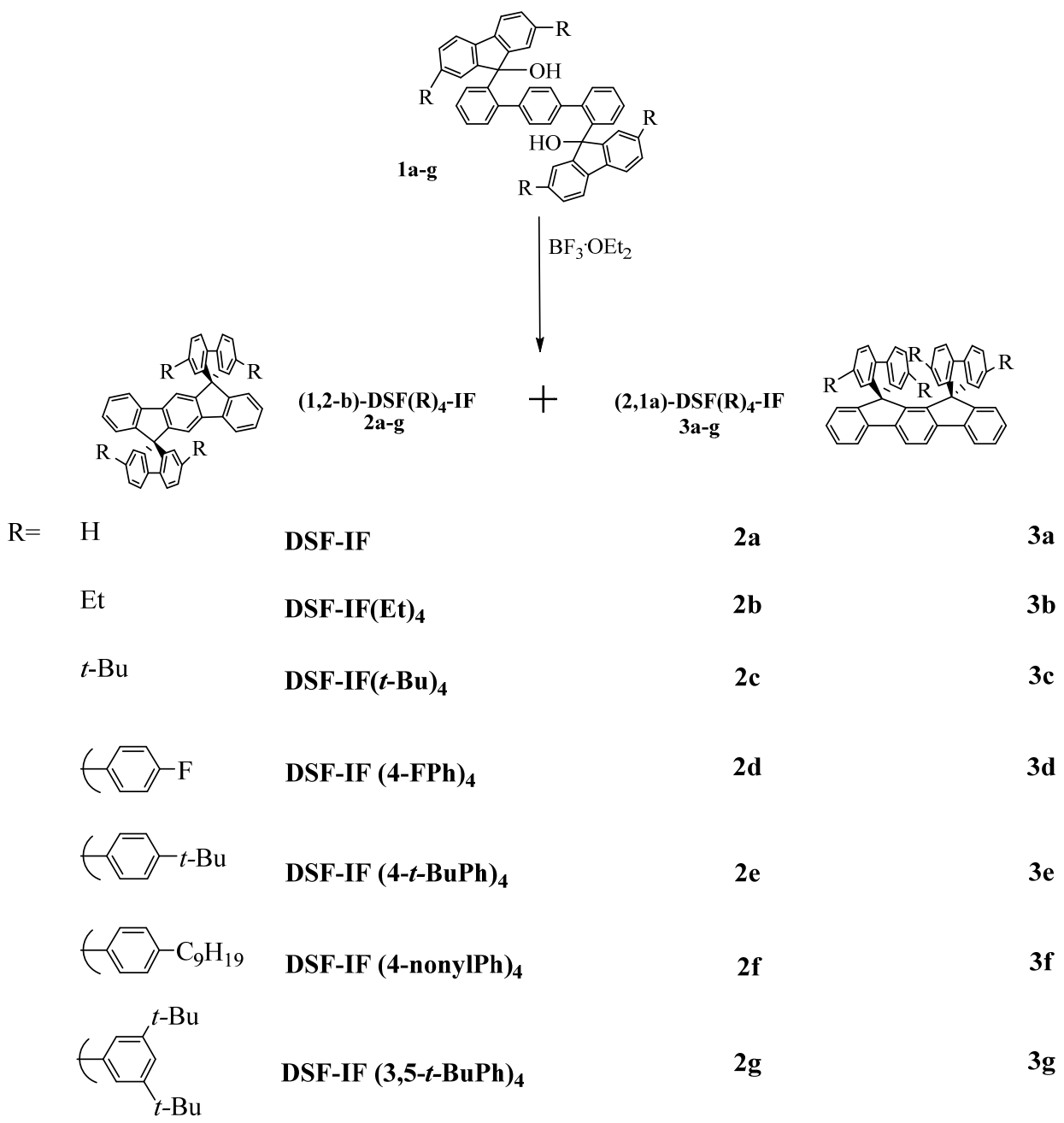

Scheme 2: Intramolecular electrophilic cyclization of difluorenols 1a-g: Synthesis of DSF-IF 2a-g and 3a-g. 
The synthesis of 2a-g and 3a-g molecules involves the treatment of the difluorenols 1a-g precursors ${ }^{[39]}$ by a Lewis acid $\left(\mathrm{BF}_{3} \mathrm{OE}\right.$ 2 2 ), Scheme 2, leading to a quantitative intramolecular bicyclization. The crude mixture was further analysed by ${ }^{1} \mathrm{H}$ NMR spectroscopy in order to determine the ratio of regioisomers $\mathbf{2}$ and $\mathbf{3}$ formed. In the present work, have also been investigated the most used cyclization conditions originally used in literature to generate spiro carbon linkages (i.e. $\mathrm{AcOH} / \mathrm{HCl}){ }^{[46]}$

Table 1. Ratio of $\mathbf{2} / \mathbf{3}$ isomers (\%) determined by ${ }^{1} \mathrm{H}$ NMR spectroscopy (all these reactions were run $1 \mathrm{~h}$ in the presence of $\mathrm{BF}_{3}$ etherate except in the case of $\mathrm{AcOH}-\mathrm{HCl}_{\mathrm{qq}}$ )

\begin{tabular}{|c|c|c|c|c|c|c|c|c|}
\hline Entry & $\mathrm{R}$ & $\begin{array}{c}\mathrm{DCM} \\
\mathrm{rt}\end{array}$ & $\begin{array}{c}\mathrm{DCM} \\
\text { reflux }\end{array}$ & $\begin{array}{c}\mathrm{CH}_{3} \mathrm{CN} \\
\mathrm{rt}\end{array}$ & $\begin{array}{c}\mathrm{CH}_{3} \mathrm{CN} \\
\text { reflux }\end{array}$ & $\begin{array}{c}\mathrm{DMSO} \\
150^{\circ} \mathrm{C}\end{array}$ & $\begin{array}{c}\mathrm{CF}_{3} \mathrm{CH}_{2} \mathrm{OH} \\
\text { reflux }\end{array}$ & $\begin{array}{c}\mathrm{AcOH}^{-} \\
\mathrm{HCl}_{\text {aq }} \\
\text { reflux }\end{array}$ \\
\hline $\mathbf{2 a} / \mathbf{3 a}$ & $\mathrm{H}$ & $99 /<1$ & $98 / 2$ & $96 / 4$ & $91 / 9$ & $94 / 6$ & $91 / 9^{[\mathrm{a}]}$ & $96 / 4$ \\
\hline $\mathbf{2 b} / \mathbf{3 b}$ & $\mathrm{Et}$ & $93 / 7$ & $91 / 9$ & $79 / 21$ & $70 / 30$ & $78 / 22$ & $87 / 13$ & $80 / 20$ \\
\hline $\mathbf{2 c / 3 c}$ & $t-\mathrm{Bu}$ & $74 / 26$ & $77 / 23$ & $33 / 67$ & $34 / 66$ & $65 / 35$ & $69 / 31$ & $43 / 57$ \\
\hline $\mathbf{2 d} / \mathbf{3 d}$ & $4-\mathrm{FPh}$ & $60 / 40$ & $56 / 44$ & $30 / 70$ & $27 / 73$ & $35 / 65$ & $37 / 63$ & $45 / 55$ \\
\hline $\mathbf{2 e} / \mathbf{3 e}$ & $4-t-\mathrm{BuPh}$ & $44 / 56$ & $39 / 61$ & $32 / 68$ & $26 / 74$ & - & - & $25 / 75$ \\
\hline $\mathbf{2 f} / \mathbf{3 f}$ & $4-$-nonylPh & $38 / 62$ & $36 / 64$ & $27 / 73$ & $16 / 84$ & $27 / 73$ & $27 / 73$ & $24 / 76$ \\
\hline $\mathbf{2 g} / \mathbf{3 g}$ & $3,5-d i-t-B u P h$ & $0 / 100$ & $0 / 100$ & $0 / 100$ & $0 / 100$ & $0 / 100$ & $0 / 100$ & $0 / 100$ \\
\hline
\end{tabular}

${ }^{\text {[a] }}$ starting materials diols was not soluble in the solvent.

\section{Case of the least encumbering and non-substituted $R=H$, reaction of $1 \boldsymbol{a}$ leading to $2 a / 3 \boldsymbol{a}$.}

We have first investigated the cyclization reaction of the non-substituted difluorenol 1a leading to the formation of the two DSF-IFs 2a/3a (Table 1). The first conditions investigated are the most common ones used in the literature to generate spiro carbon linkages, i.e. acetic acid/HCl-reflux. ${ }^{[3]}$ In these conditions, the cyclization of 1a provides a mixture of the two regioisomers 2a/3a, the 2a isomer being however strongly favoured (2a/3a: 96/4). The modification of the reaction conditions strongly alters the ratio of isomers formed. The cyclization of 1a performed in an apolar ${ }^{[47]}$ solvent such as dichloromethane at room temperature is almost fully regioselective providing almost exclusively the isomer $\mathbf{2 a}$ with only formation of less than $1 \%$ of the other isomer 3a. However, switching to more polar and donor solvent, ${ }^{[4]}$ such as acetonitrile, the amount of 3a over $2 \mathbf{2 a}$ at room temperature consistently increases remaining nevertheless very low (4\%). Interestingly, the temperature of the reaction allows to increase the amount of $\mathbf{3 a}$ and seems to have a significant effect on the ratio of isomers formed. In acetonitrile, the $\mathbf{2 a}$ /3a distribution is $\mathbf{9 6 / 4}$ at room temperature and is $91 / 9$ at reflux. Thus, switching to a higher temperature and/or to a more polar and donor solvent $\left(\mathrm{CH}_{3} \mathrm{CN}\right.$, DMSO and $\mathrm{CF}_{3} \mathrm{CH}_{2} \mathrm{OH}$, Table 1) the amount of 3a over 2a consistently increases, reaching a maximum of $9 \%$ at the reflux of $\mathrm{CH}_{3} \mathrm{CN}$ or $\mathrm{CF}_{3} \mathrm{CH}_{2} \mathrm{OH}$. Despite moderate in the present case, these effects will be stronger in the examples discussed next where the fluorene moieties bear different substituents.

\section{Case of aliphatic substitution $R=E$ t, reaction of $\mathbf{1 b}$ leading to $\mathbf{2 b} / 3 \boldsymbol{b}$.}

The incorporation of an ethyl group on the 2,7-positions of the fluorene moieties (ethyldifluorenol $\mathbf{1 b}$, Scheme 2) leads to a significant alteration of the ratio of isomers formed (2b/3b) compared to 2a/3a. Indeed, in dichloromethane and acetonitrile at room temperature, the ratio of isomer $3 \mathbf{b}$ respectively reaches $7 \%$ and $21 \%$, a significant increase compared to the ratio of

\footnotetext{
${ }^{*}$ It is important to mention that for all the solvents investigated in this study, no cyclization reaction was detected prior to the addition of acid.
} 
its unsubstituted analogue $\mathbf{3 a}$ in the same conditions (less than $1 \%$ and $4 \%$ respectively, Table 1). More impressively, the amount of $\mathbf{3 b}$ over $\mathbf{2} \mathbf{b}$, in polar and donor solvents (reflux), $\mathrm{CH}_{3} \mathrm{CN}$ (2b/3b: 70/30), DMSO (2b/3b: 78/22) and $\mathrm{CF}_{3} \mathrm{CH}_{2} \mathrm{OH}$ (2b/3b: 87/13), is significantly enhanced compared to the amount of 3a over 2a, reaching a maximum of $30 \%$ at reflux of acetonitrile, Table 1 . At this stage, one can hence conclude that increasing the steric hindrance on the fluorene units of the starting difluorenol (through the incorporation of ethyl groups) has a significant effect on the regioselectivity of the reaction. This feature is nevertheless surprising at first sight as it clearly favours the more encumbered 3-type isomer possessing a cofacial arrangement of the fluorene moieties that is the less energetically stable isomer (vide infra). As stated above in the case of $\mathbf{2 a / 3 a}$, the temperature is also of great importance on the $\mathbf{2} \mathbf{b} / \mathbf{3} \mathbf{b}$ isomers distribution. Note that the cyclization cannot be run at room temperature in DMSO and $\mathrm{CF}_{3} \mathrm{CH}_{2} \mathrm{OH}$ because of the poor solubility of the reactants.

Thus, the increase of (i) the temperature of the reaction, (ii) the steric hindrance (substitution of fluorene units with ethyl groups) and (iii) the polarity and donor ability of the solvent all increase the amount of type- 3 isomers, albeit the most sterically hindered and less energetically isomers (Table 2).

\section{Case of a more encumbering aliphatic substituent $R=t-B u$, reaction of $1 c$ leading to $2 c / 3 c$.}

Although the solvents and temperature effects seem to follow a similar trend for the cyclization of $\mathbf{1 a}$ and $\mathbf{1 b}$, the preferentially formed isomer is always the type-2 isomer (2a or $\mathbf{2} \mathbf{b}$ ). Since the steric hindrance has a crucial impact on the regioselectivity of the reaction, bulky $t$-butyl groups were introduced on the 2,7-positions of the fluorene units to confirm this hypothesis. Thus, at room temperature, the $\mathbf{2 c / 3 c}$ ratio is $74 / 26$ in dichloromethane and is almost fully reversed in acetonitrile, 33/67. Compared to the series $\mathbf{a}$ and $\mathbf{b}$ presented above, we thus noted that the ratio of 3-type isomers is impressively enhanced in all the solvents: from less than $1 \%$ for $\mathbf{3 a}$ to $7 \%$ for $\mathbf{3 b}$ and up to $26 \%$ for $3 \mathbf{c}$ in dichloromethane (at room temperature) and from $4 \%$ for $3 \mathbf{a}$ to $21 \%$ for $\mathbf{3 b}$ and up to $67 \%$ for $\mathbf{3 c}$ in acetonitrile (at room temperature). The distribution of $\mathbf{2 c} / \mathbf{3 c}$ ratio was hence strongly modified compared series a and b (vide supra), highlighting the importance of the steric hindrance in this cyclization reaction. Thus, the ratio of 3-type isomers seems directly related to the bulkiness of the substituents borne by the starting difluorenols ( $t$ butyl for $\mathbf{1 c}>$ ethyl for $\mathbf{1 b}>$ hydrogen for 1a). Interestingly, when the bulkiness of the R group is sufficiently large such as in $\mathbf{2} \mathbf{c} / \mathbf{3 c}$, the observed tuning range through solvent effects is also the largest. This is a key point. One can hence conclude from this first series of cyclization reactions of alkyl-substituted difluorenols 1a-c that (i) low polarity and weakly donor solvent, (ii) low temperature and (iii) small R groups on the fluorene moieties all favour the synthesis of 2-type positional isomers. The opposite conditions lead gradually and preferably to the 3type isomers although they are more encumbered and less energetically stable than the 2-type isomers (Table 2). The three effects involved in the ratio of isomers formed need to be addressed herein: the effect of substitution at the fluorene moieties, the solvent effect and the temperature effect. To assist this discussion, molecular modelling of the type-2 and type-3 isomers, the pro2 or pro-3 conformers and their corresponding transition state towards the Wheland intermediates have been performed.

\section{Molecular modelling of pro-2a/3a and pro-2c/3c transition states}

For such reaction considered as an addition/elimination process, it is widely admitted that the electrophile interacts with the $\pi$-system passing through a sigma bonded intermediate (called sigma complex, arenium ion or Wheland intermediate) and leading to the final product. ${ }^{[48]}$ As 
stated by Sainsbury in the book 'Aromatic Chemistry', "the true nature of the transition state is not easily predicted, but it is reasonable to assume that the transition state resembles the sigma complex" ${ }^{[48]}$ However, in the present case, the Wheland intermediate cannot be involved in the regioselectivity of the reaction as the double cyclization has already been done and the syn or anti configuration is already fixed. In order to explain the formation of the two regiosomers, we reasonably assume that the bicyclization reaction unfolds sequentially (Scheme 3). The first cyclization leads to a carbocation with a spirobifluorene core, substituted at its C2 carbon by a pendant phenyl unit, itself ortho-substituted by a fluorene group linked through its C9 carbon. At this stage, we consider the formation of interconvertible carbocationic pro-2 or pro-3 conformers which afford during the second cyclization steps the corresponding Wheland-type intermediate ${ }^{[15]}$ that finally leads to the regioisomers $\mathbf{2 / 3}$ (Scheme 3) after deprotonation.

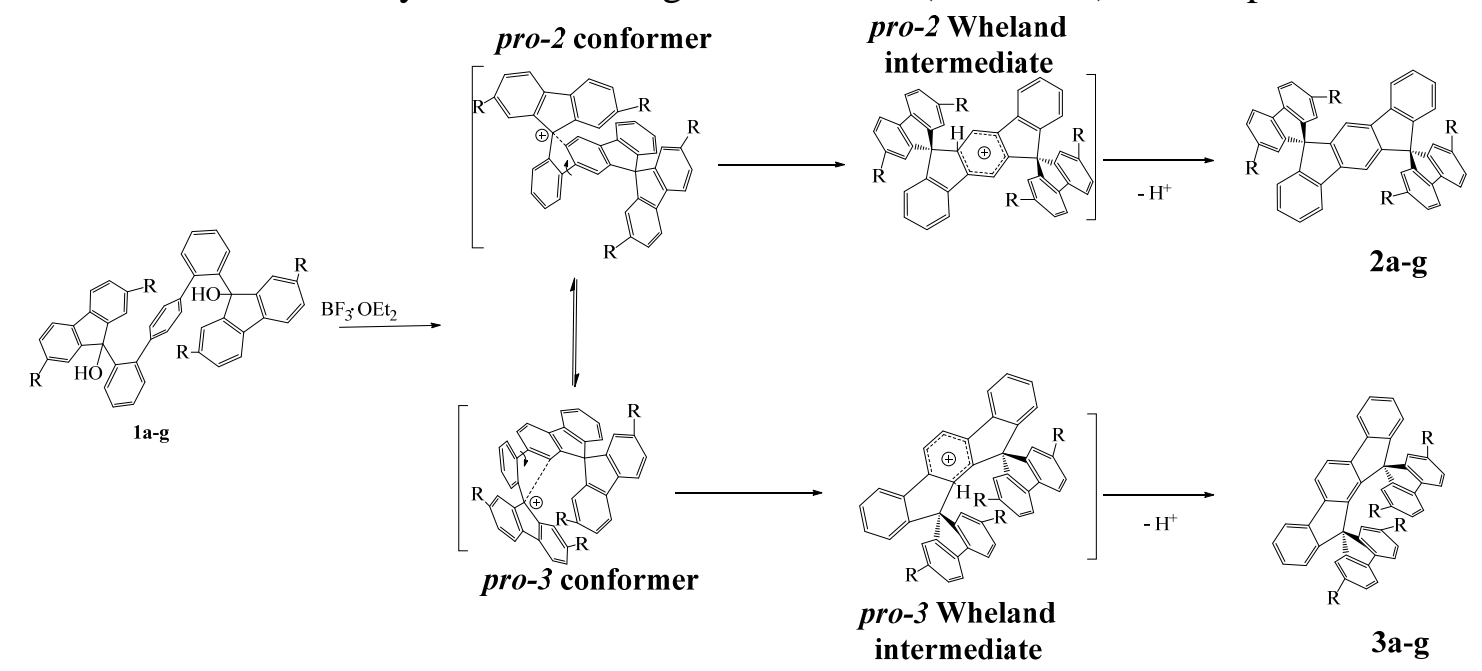

Scheme 3: Cyclization of difluorenols 1a-g and the corresponding intermediates postulated in the mechanism of formation of regioisomers $2 \mathbf{a}-\mathbf{g} / 3 \mathbf{a}-\mathbf{g}$.

It is hence relevant to examine theoretically the structure and energy of these intermediates and transition states in the pro-2 and pro-3 conformation (Scheme 3) as a function of the nature of the substitution at the fluorene units. However, it is first important to state that irrespective of the substitution of the fluorene units, type- 2 isomers are always thermodynamically more stable than their type-3 analogues (Table 2). Indeed, in type-3 isomers, the steric hindrance induced by the two cofacial fluorene units leads to less stable molecules compared to the type- 2 isomers with the two fluorene units on two opposite sides of the dihydroindenofluorene core. Thus, the difference in stability is $0.36 \mathrm{eV}(8.30 \mathrm{kcal} / \mathrm{mol})$ and $0.34 \mathrm{eV}(7.84 \mathrm{kcal} / \mathrm{mol})$ for $2 \mathrm{a} / 3 \mathbf{3 a}(\mathrm{R}=\mathrm{H})$ and $\mathbf{2 b} / 3 \mathbf{b}(\mathrm{R}=\mathrm{Et})$ respectively. Branching a bulkier group on the fluorene $(2 \mathrm{c} / \mathbf{3 c} \mathrm{R}=t-\mathrm{Bu})$ increases the relative stability of the type-2 isomer to $0.51 \mathrm{eV}(11.76 \mathrm{kcal} / \mathrm{mol})$. As we have shown experimentally that the more the difluorenol is encumbered the more the reaction becomes selective towards type- 3 isomers, the difference observed in the relative stability of the two isomers indicates that this is certainly not a key parameter in the selectivity observed in the bicyclization reaction. Rather the encumbrance at the level of the transition state before cyclization to the Wheland intermediate is likely to be more relevant, as discussed next. 
Table 2: Calculated relative stability of 2a-g vs. 3a-g.

\begin{tabular}{|c|c|c|c|c|c|c|c|}
\hline Entry & $\mathbf{2 a} / \mathbf{3 a}$ & $\mathbf{2 b} / \mathbf{3 b}$ & $\mathbf{2 c / 3 \mathbf { c }}$ & $\mathbf{2 d / 3 d}$ & $\mathbf{2 e / 3 e}$ & $\mathbf{2 f / 3 f *}$ & $\mathbf{2 g / 3 g}$ \\
\hline $\begin{array}{c}\Delta \mathrm{E}(\mathrm{eV}) \\
(\mathrm{kcal} / \mathrm{mol})\end{array}$ & $\begin{array}{c}0.36 \\
(8.30)\end{array}$ & $\begin{array}{c}0.34 \\
(7.84)\end{array}$ & $\begin{array}{c}0.51 \\
(11.76)\end{array}$ & $\begin{array}{c}0.34 \\
(7.84)\end{array}$ & $\begin{array}{c}0.38 \\
(8.76)\end{array}$ & $\begin{array}{c}0.37 \\
(8.53)\end{array}$ & $\begin{array}{c}0.48 \\
(11.07)\end{array}$ \\
\hline
\end{tabular}

*Calculations have been performed with an ethyl chain instead of a nonyl chain.

For $\mathrm{R}=\mathrm{H}$ the energy of the pro-2a or pro-3a carbocation conformers only differs by $0.04 \mathrm{eV}$ $(0.92 \mathrm{kcal} / \mathrm{mol})$ and that of the corresponding Wheland intermediates lies higher in energy (by $0.17(3.92 \mathrm{kcal} / \mathrm{mol})$ and $0.55 \mathrm{eV}(12.68 \mathrm{kcal} / \mathrm{mol})$ respectively $){ }^{28}$ A similar trend is found for the $\mathrm{R}=\mathrm{Et}$ and $\mathrm{R}=t$-Bu derivatives. Examination of the transition states between the carbocations and the Wheland intermediates for $\mathrm{R}=\mathrm{H}$, Et or $t$-Bu shows that they lie at about $0.55 \mathrm{eV}(12.68$ $\mathrm{kcal} / \mathrm{mol})$ higher than the corresponding pro-2 carbocation and ca. $0.80 \mathrm{eV}(18.45 \mathrm{kcal} / \mathrm{mol})$ higher than the corresponding pro-3 carbocation. In other words, although the $\mathbf{2} / \mathbf{3}$ ratio changes as the substituent encumbrance increases the calculated energy of the transition states remains very similar from $\mathbf{2 a}$ to $\mathbf{2 c}$ and decreases only slightly from 3a to 3c. Consequently, there is at first sight only a subtle energy trend that could explain the differences in the increasing ratio toward the type $\mathbf{3}$ isomer as the bulkiness of the R group increases. It must be concluded that, although all intermediates are energetically accessible, increased bulkiness of the $\mathrm{R}$ group gradually prevents the facile structural access to the pro-2 transition state. This can be illustrated in Figure 1 where the two calculated pro-2a and pro-3a transition states $(\mathrm{R}=\mathrm{H})$ are pictured. Although free of any steric hindrance, the optimized structure of the pro-2a transition state (Figure 1, left) ${ }^{*}$ shows that any substitution at the 2,7-positions on each fluorene group (see $\mathrm{H} 2$ and $\mathrm{H7}$ coloured in blue in Figure 1) will inevitably lead to an encumbrance between the substituents. We believe that this structural feature is at the origin of the selectivity observed herein. As the size of $\mathrm{R}$ increases, the actual accessibility to the pro-2 transition state should then be more difficult compared to that of the pro-3 transition state. This becomes more evident when comparing the optimized geometry of the pro-2c and pro-3c transition states with the bulkier $t$-Bu substituent (Figure 2). We reckon that the key explanation to the selectivity of this sequential and irreversible reaction as a function of the size of $\mathrm{R}$, lies in the respective structure and encumbrance of the two pro- 2 and pro-3 transition states.

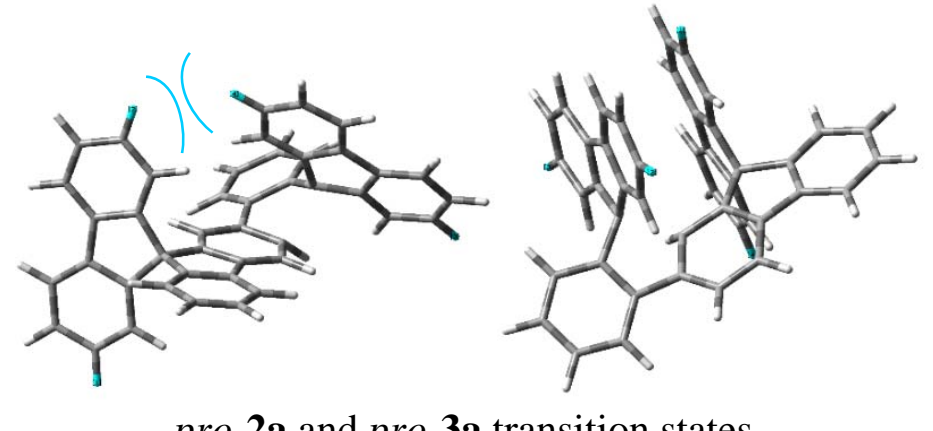

pro-2a and pro-3a transition states

Figure 1: Views of transition states of pro-2a (left) and pro-3a (right). Substitution at the position of hydrogen atoms coloured in blue will inevitably induce steric hindrance in the pro2 transition states (left) but not in the pro-3 transition states (right).

\footnotetext{
${ }^{*}$ All the log files with the (attempted) optimized geometry are available as supporting information for viewing and manipulating the structures presented in Figures 1-4 (see experimental part)
} 

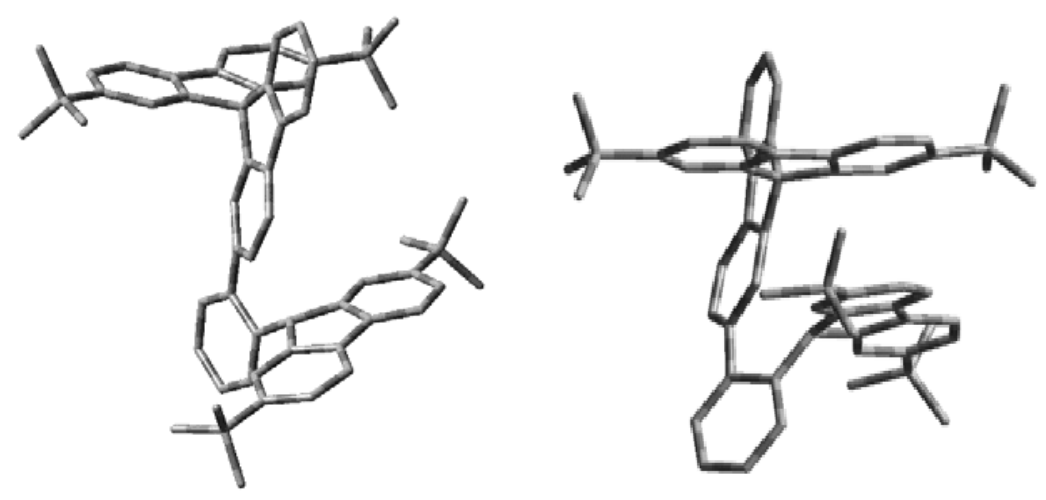

pro-2c and pro-3c transition states

Figure 2: Views of transition states of pro-2c (left) and pro-3c (right) with hydrogen atoms omitted for clarity.

5. Case of encumbering para-substituted phenyl substituents $R=4$-fluoro-phenyl; 4-t-butylphenyl or 4-nonyl-phenyl, reaction of $\mathbf{1 d - f}$ leading to $\mathbf{2 d - f / 3 d - f .}$

In order to confirm that the regioselectivity of this reaction finds its origin in the encumbrance of the fluorene units of the two pro-2 and pro-3 transition states, three other systems have been investigated. In this second step, para-substituted phenyl rings were introduced on the fluorene units to extend the study of the influence of such bulky substituents on the cyclization reaction. In the light of the structure of the pro-2a and pro-2c transition states presented above, the goal of increasing the length of the substituents borne by the fluorene was to disfavour access to the pro-2 transition states. We investigated difluorenol derivatives substituted with 4-fluoro-phenyl (1d); 4-t-butyl-phenyl (1e) and 4-nonyl-phenyl (1f). The three different substituents borne by the aryl ring (-F, $-t-\mathrm{Bu}$, and $\left.-\mathrm{C}_{9} \mathrm{H}_{19}\right)$ possess different size and these substituents should increase the amount of type $\mathbf{3}$ isomers formed at the expense of type $\mathbf{2}$ isomers.

Compared to the difluorenols 1a-c bearing relatively small substituents directly connected to the fluorene units, the cyclization of aryl-substituted difluorenols 1d-f led in all case to an impressive increase of the amount of the isomer 3 , Table 1 . However, when branching the fluorene units with a para-substituted phenyl moiety (2d-f/3d-f) the relative stability of the type-2 isomers is similar to that of the unsubstituted (2a/3a) or the ethyl substituted fluorene ( $2 \mathbf{b} / 3 \mathbf{b}$ ) isomers ( 0.34 to $0.38 \mathrm{eV}$ range, 7.84 to $8.76 \mathrm{kcal} / \mathrm{mol}$ ), Table 2 . This trend shows that the effect of the encumbrance of a para-substituted phenyl group is low and does not significantly affect the magnitude of the relative stability of the type-2 isomers compared to unsubstituted or alkyl-substituted fluorene groups. Again, this parameter cannot be taken into account to explain the regioselectivity.

The cyclization of the 4-fluorophenyl-difluorenol 1d, bearing the smallest substituent in para

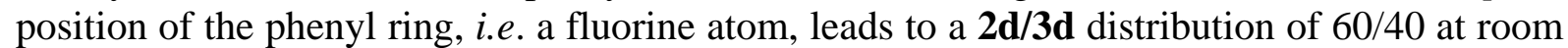
temperature in dichloromethane. By increasing the temperature, the $\mathbf{2 d / 3 \mathbf { d }}$ distribution is $56 / \mathbf{4 4}$, highlighting as noted above that the amount of $\mathbf{3 d}$ is slightly increased by thermal input. Thus, in these conditions, the ratio of the type 3-isomer is significantly increased compared to alkyl substituted fluorenols (from $23 \%$ for 3 c to $44 \%$ for $3 \mathbf{d}$ ) but the general trend is the same. In polar solvents, the amount of $\mathbf{3 d}$ is strongly increased compared to non-polar solvents, reaching $63 \%$ in $\mathrm{CF}_{3} \mathrm{CH}_{2} \mathrm{OH}, 65 \%$ in DMSO and $73 \%$ in acetonitrile. The isomer $\mathbf{3 d}$ is now the major isomer formed in all the polar solvents tested. This is a striking difference compared to the case of isomers 2a-c/3a-c discussed above. 
By increasing the size of the substituent in para position of the phenyl ring with a $t$-butyl group (1e) or a nonyl chain (1f), the regioselectivity toward the type-3 isomer was further increased. The amount of type-3 isomer goes from $40 \%$ for $3 \mathbf{d}$, to $56 \%$ for $3 \mathbf{e}$ and to $62 \%$ for $\mathbf{3 f}$ in dichloromethane at room temperature. Increasing the temperature leads again to a slight enhancement of the type-3 isomers. When the reaction is carried out in polar solvents, the amount of $\mathbf{3 e}$ and $\mathbf{3 f}$ is again increased clearly confirming the trend exposed above. Thus, at the reflux of acetonitrile, the ratio of $3 \mathbf{e}$ reaches $74 \%$ and that of $\mathbf{3 f}$ reaches $84 \%$. The latter case is the highest regioselectivity toward type-3 isomer found for this series of compounds.

Regarding the effect of the temperature, of the solvent and of the size of the substituents borne by the fluorene units, the same trend is hence observed for all these molecules (bearing alkyl or aryl groups). Nevertheless, in the aryl series, it is important to mention that in polar solvents i.e. DMSO, MeCN and $\mathrm{CF}_{3} \mathrm{CH}_{2} \mathrm{OH}$, the major isomer obtained is now always the type-3, which was not the cases with small alkyl substituents. Thus, examination of the results compiled in Table 1 clearly shows that as $\mathrm{R}$ becomes more encumbering (from $\mathrm{R}=\mathrm{H}$ to $\mathrm{R}=4$-nonylphenyl), the distribution of isomers gradually shifts towards the formation of type- 3 at the expense of type- 2 molecules. As the bulkiness of the $\mathrm{R}$ group changes from small to large, the isomer distribution becomes even almost totally reversed $(\mathbf{2 a} / \mathbf{3 a}=99 / 1$ and $\mathbf{2 f} / \mathbf{3 f}=16 / 84)$.

\section{Molecular modelling of pro-2d/3d and pro-2e/3e transition states}

Consideration of the optimized geometry of the transition states between the carbocation and the Wheland intermediate, the aryl-substituted compounds (2d-f/3d-f) display the same expected features as the previously discussed alkyl or unsubstituted congeners (2a-c/3a-c). Indeed, as can be seen in Figure 3 (and with the manipulation of the optimized geometry files provided as supporting information), the introduction of a para-substituted phenyl substituent at the fluorene moieties, (here with the pro-2d/3d $\mathrm{R}=\mathrm{PhF}$ (top) and pro-2e/3e $\mathrm{R}=\mathrm{Ph}-t-\mathrm{Bu}$ (bottom) taken as examples) leads to a potential steric hindrance at the level of the transition state between two phenyl groups from opposite fluorene moieties (Figure 3, left).

The increased length and encumbrance brought about by the para-substituted phenyl at the 2.7 position of the fluorene moieties does not affect the accessibility to the pro-3 transitions states structure (Figure 3, right) as it can be visualized by manipulating the structures provided in the supporting information: Lengthening the longitudinal substitution at the fluorene 2,7 position do not provoke an encumbrance between the substituents of opposite fluorene groups. On the contrary this steric hindrance between the substituents of opposite fluorene groups in the pro-2 isomers (Figure 3, left) can be anticipated and is better appreciated by by manipulating the structures provided in the supporting information. Regarding the relative energy between the carbocation and the transition states for the alkyl- or non-substituted $(\mathrm{R}=\mathrm{H})$ congeners $v s$. the aryl substituted ones, one notes that this energy gap increases more significantly in the case of the pro-2 isomers (for example by ca. $0.15 \mathrm{eV}$ or $3.46 \mathrm{kcal} / \mathrm{mol}$ for pro-2d $v s$. pro-2a) than for the pro-3 isomers where the values are closer (for example by ca. $0.02 \mathrm{eV}$ or $0.46 \mathrm{kcal} / \mathrm{mol}$ for pro-3d vs. pro-3a). Again, this energy trend is subtle but consistent with the increased ratio of 3-type isomers with increased bulkiness of the fluorene substituents. Thus, the size of the substituents grafted on the fluorene units leads to pro-2 and pro-3 transitions states possessing drastically different steric hindrance, which undoubtedly drives the regioselectivity of the isomers formed. However, one cannot exclude at this stage, an additional effect at the transition state between the two pro-2 and pro-3 carbocation rotamers, although molecular modeling failed to provide support for this latter hypothesis as no relevant transition state were found between the rotamers. 

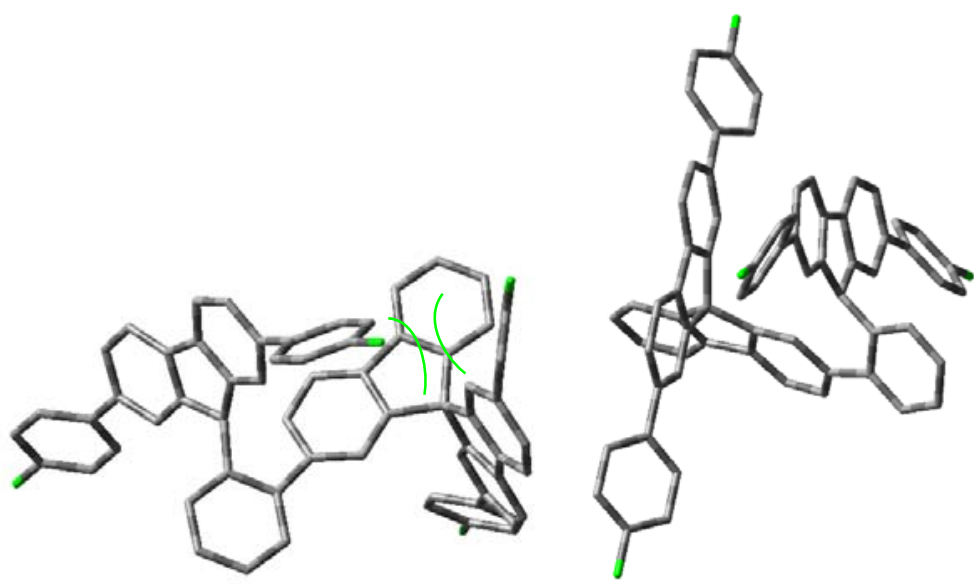

pro-2d and pro-3d transition states
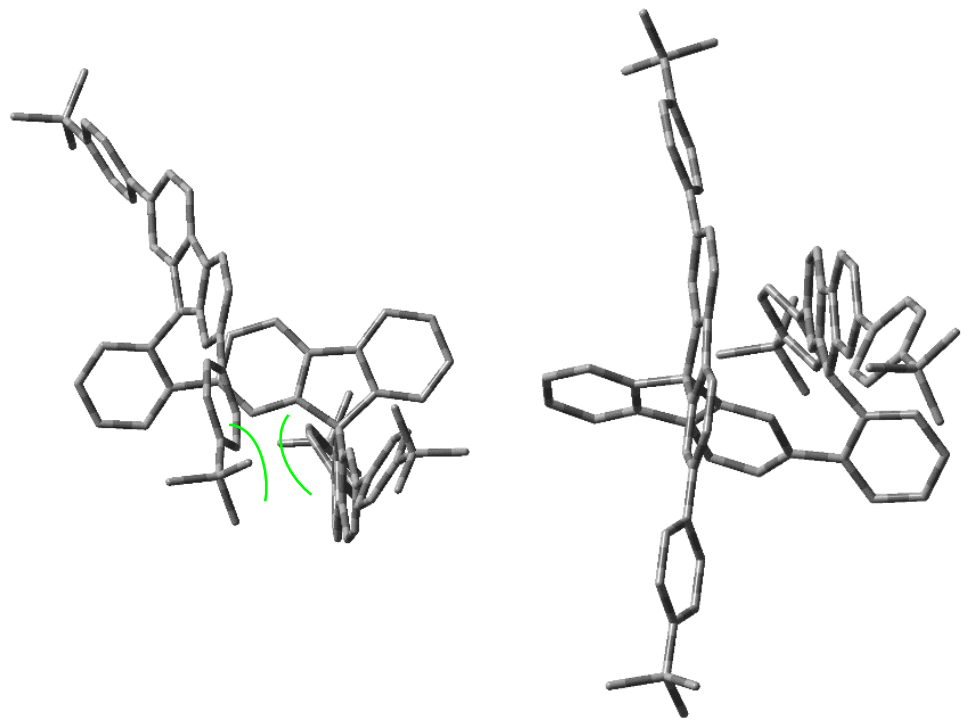

pro-2e and pro-3e transition states

Figure 3: Views of transition states of pro-2d (top left) and pro-3d (top right), pro-2e (bottom left) and pro-3e (bottom right) with hydrogen atoms omitted for clarity, fluorine atoms appear in green.

7. Case of the very bulky meta-substituted $R=3,5-d i-t$-butylphenyl substituent, reaction of $\mathbf{1 g}$ leading exclusively to $\mathbf{3 g}$.

As the results presented above clearly evidence that the steric hindrance induced by the substituents allows to increase the selectivity towards the type-3 isomer, a very bulky substituent has been finally investigated. However, to regioselectively obtain a type-3 isomer, the phenyl substituent should be functionalized in meta positions and not in para in order to completely prevent the formation of type-2 isomers. Thus, the bulky 3,5-di-t-butylphenyl fluorenol $1 \mathrm{~g}$ was investigated, bearing two bulky $t$-Bu groups in meta positions of the phenyl ring and a regioselective reaction was observed. Indeed, in all the investigated solvents, the cyclization of $\mathbf{1 g}$ exclusively leads to the formation of the isomer $\mathbf{3 g}$ with no trace of the other 
isomer $\mathbf{2 g}$. In this last example, the relative stability of the type-2 isomer (0.48 eV or 11.07 $\mathrm{kcal} / \mathrm{mol}$, Table 2) is nevertheless similar to that of the $t$-Bu substitution case $(2 \mathrm{c} / 3 \mathrm{c})(0.51 \mathrm{eV}$, $11.76 \mathrm{kcal} / \mathrm{mol}$ ) confirming the conclusions drawn above. Unfortunately, molecular modelling of the pro-3g transition state failed to converge to a stable structure which we assign in part to the number of rotating $t$-Bu groups in the molecule. However, a structure of a plausible pro-3g transition state and consistent with transition states obtained for other type $\mathbf{3}$ isomers is nevertheless presented in Figure 4 (middle) together with the optimized pro-3g carbocation (left) and the optimized pro-3g Wheland intermediate (right). The reaction is quantitatively regioselective and Figure 4 represents the credible sequence toward the least energetically stable isomer $\mathbf{3 g}$. It is important to note that calculations attempts of the pro-2g transition state yielded irrelevant structures with respect to cyclization toward the Wheland intermediate.
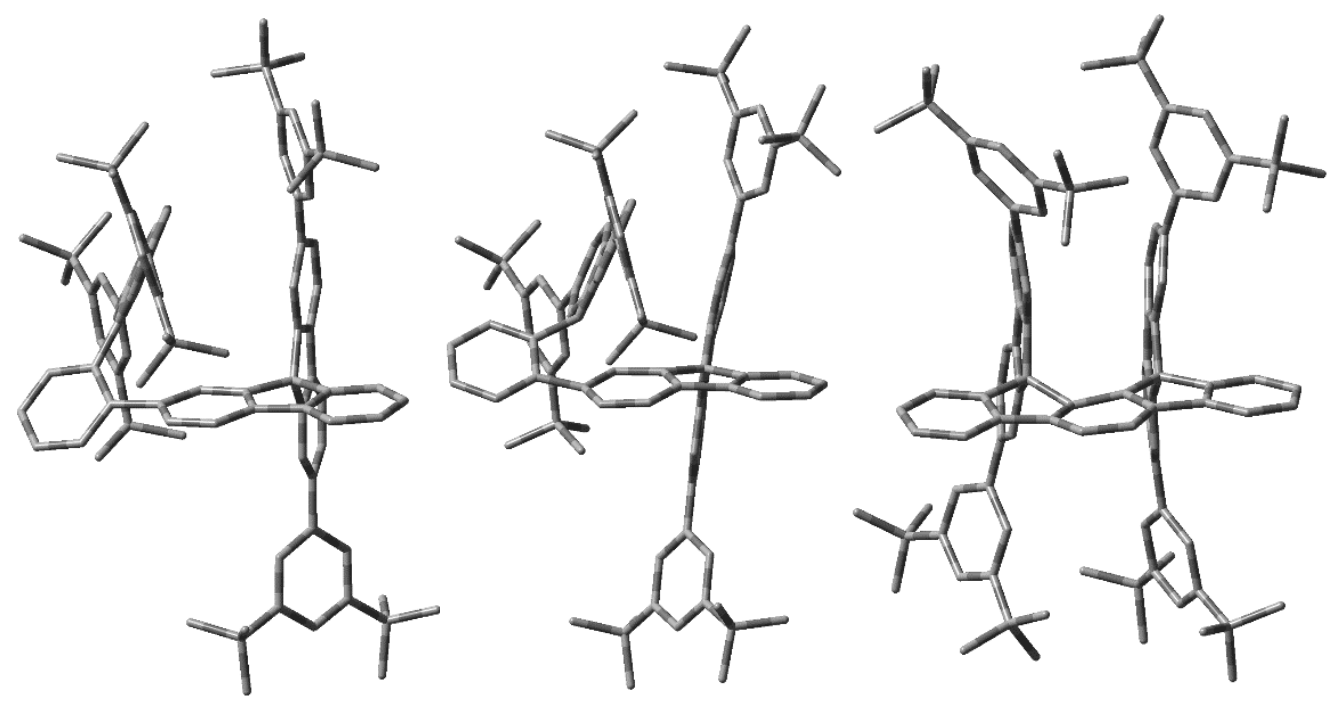

pro-3g carbocation

Estimated pro-3g transition state

pro-3g Wheland intermediate

Figure 4: Views of optimized geometry of the pro-3g carbocation (left) and Wheland intermediate (right). The estimated structure of pro-3g transition state (middle) is given as illustration only as the calculation failed to converge to a stable structure. Hydrogen atoms are omitted for clarity.

This example clearly highlights the direct influence of the steric hindrance induced by the substitution of the phenyl rings on the regioselectivity of the reaction.

\section{Conclusion}

In summary, the cyclization of alkyl- and aryl-substituted difluorenols 1a-g appears to be connected to the same parameters. Indeed, low polarity and weakly donor solvents, low temperature and small substituents on the fluorene moieties all favour the synthesis of 2-type positional isomers. However, the most important feature, which drives the regioselectivity is directly linked to the size and the position of the substituents borne by the fluorene units. Indeed, a small substituent induces the formation of type-2 positional isomers whereas a bulky one leads to the other family of regioisomers, i.e. type-3 positional isomers. In the light of the steric hindrance of the transition states, the origin of the regioselectivity has been pinpointed and is 
not related to the relative stability of the regioisomers themselves (Table 2) but to the relative structure and accessibility of the transition states.

As the three parameters involved, i.e. solvent, temperature and steric hindrance can be combined in many different ways, we are convinced that this cyclization reaction still deserves to be investigated to fully explore its potential. Our recent works on the same cyclization reaction involving a different central terphenyl backbone possessing a meta linkage ${ }^{[4,49]}$ instead of a para linkage show the importance of the fluorene rotation on the selectivity of the reaction, Figure 5. Indeed, preliminary results presented in Figure 5 show that the syn $[2,1-b]$ isomer is almost always favoured (with either $\mathrm{R}=\mathrm{H}$ or $\mathrm{R}=t$-Bu) over the anti $[1,2-a]$ isomer with a degree of modulation of the regioselectivity far less important than for the $[2,1-a] /[1,2-b]$ couple reported here. These results show the peculiarity of the present systems and the importance of the central terphenyl backbone on the selectivity of the cyclization reaction.

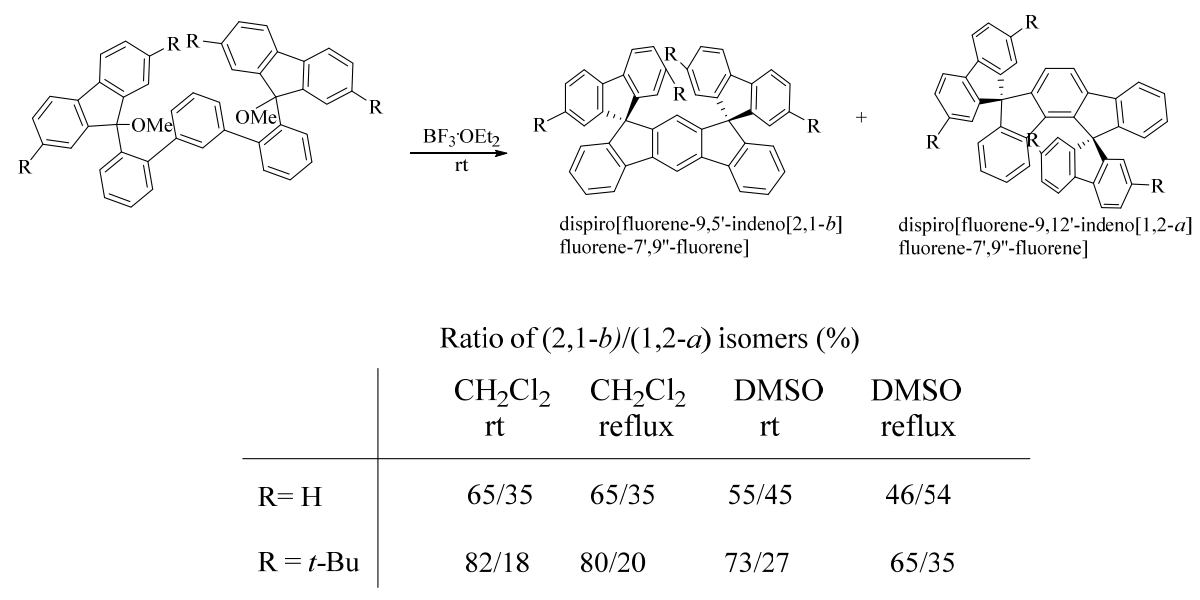

Figure 5. Top. Synthesis of a different generation of dispirofluorene-Indenofluorene postional isomers constructed on the meta terphenyl backbone. Bottom. ratio of isomers formed (\%, determined by ${ }^{1} \mathrm{H}$ NMR spectroscopy). 


\section{Acknowledgments.}

DT thanks the Région Bretagne for a studentship. We thank Dr Maxime Romain (University of Rennes 1) for his help in some cyclization experiments and the first results on the cyclization of meta difluorenol compounds. This work was granted access to the computing ressources of CINES (Montpellier, allocation 2018-A0020805032 awarded by GENCI).

\section{Experimental section}

Synthesis. The synthesis/characterization of the difluorenols 1a-g and the characterizations of corresponding DispiroFluorene-IndenoFluorenes 2a-g and 3a-g have been previously reported. ${ }^{[39]}$

General procedure for the cyclization reactions: Difluorenol 1a-g (10 $\mathrm{mg})$ was dissolved in the solvent $(10 \mathrm{~mL})$ and stirred for $15 \mathrm{~min}$ at room temperature or at the reflux of the solvent. Boron trifluoride etherate $\left(48 \% \mathrm{BF}_{3}\right)(5 \mu \mathrm{L})$ was added and the resulting mixture was stirred for one hour (until total conversion of the starting difluorenol) at the desired temperature. The crude mixture was evaporated to dryness and the ratio of isomers determined by ${ }^{1} \mathrm{H}$ NMR.

In the case of cyclization reactions in $\mathrm{AcOH}$, a slightly different procedure was performed. $\mathrm{AcOH}(10 \mathrm{~mL})$ was heated to reflux before to add difluorenol 1a-g $(10 \mathrm{mg})$ and $20 \mu \mathrm{L}$ of concentrated hydrochloric acid (35\%) was added and the resulting mixture was stirred for one hour (until total conversion of the starting difluorenol) at the desired temperature. The crude mixture was evaporated to dryness and the ratio of isomers determined by ${ }^{1} \mathrm{H}$ NMR.

\section{Molecular modelling.}

Files with the optimized geometry are available as supporting information for viewing and manipulating the structures: S1pro2aTS.log and S2pro3aTS.log (Figure 1); S3pro2cTS.log and S4pro3cTS.log (Figure 2); S5pro2dTS.log, S6pro3dTS.log, S7pro2eTS.log and S8pro3eTS.log (Figure 4); S9pro3gTS.log, S10pro3gCat.log, and S11pro3gW.log (Figure 5).

Transition states geometry optimizations were performed using Density Functional Theory ${ }^{[50,}$

${ }^{51]}$ using the default convergence criteria implemented in the Gaussian software, ${ }^{[52]}$ version 2003/D02 or more recent releases. The hybrid Becke-3 parameter exchange functional ${ }^{\text {[53-55] }}$ and the Lee-Yang-Parr non-local correlation functional ${ }^{[56]}$ (B3LYP) were used together with the 6-31G* basis set. ${ }^{[57]}$ Either a guessed structure of the transition state was used as input with the opt=TS keyword or two structures of the previously optimized carbocations and Wheland intermediates $^{[41]}$ were used as input with the opt=QST2 keyword. Full convergence was obtained for all transition state models considered with the exception of pro-3g. Frequency calculations for pro-2a/3a, pro-2c/3c and pro-3d showed only one significant negative frequency around $-300 \mathrm{~cm}^{-1}$. No further frequency calculations were carried out. Despite the failed convergence of the transition state of pro-3g assigned to the rotation of the $8 \mathrm{t}$-Bu groups (or 24 Me groups), the structure obtained by the optimization sequence has been used for an illustration purpose. Attempts to optimize the transitions states between the rotamers of the carbocations or of the transition state of pro-2g led to irrelevant structures. The .log files of the selected structures presented in the paper are provided as supporting information so that they can be readily opened and manipulated with the GaussView (version 5.0.9) software that was used to generate the Figures. 


\section{References}

[1]L. Sicard, H.-C. Li, Q. Wang, X.-Y. Liu, O. Jeannin, J. Rault-Berthelot, L.-S. Liao, Z.-Q. Jiang, C. Poriel, Angew. Chem. Int. Ed. 2019, 58, 3848-3853.

[2]C. Poriel, J. Rault-Berthelot, J. Mater. Chem. C 2017, 5, 3869-3897

[3]T. P. I. Saragi, T. Spehr, A. Siebert, T. Fuhrmann-Lieker, J. Salbeck, Chem. Rev. 2007, 107, 1011-1065.

[4]M. Romain, D. Tondelier, J.-C. Vanel, B. Geffroy, O. Jeannin, J. Rault-Berthelot, R. Métivier, C. Poriel, Angew. Chem. Int. Ed. 2013, 52, 14147-14151.

[5]L.-H. Xie, J. Liang, J. Song, C.-R. Yin, W. Huang, Curr. Org. Chem. 2010, 14, 2169-2195.

[6]S. Lee, B. Kim, H. Jung, H. Shin, H. Lee, J. Lee, J. Park, Dyes Pigm. 2017, 136, 255-261.

[7]H. Lee, H. Jung, S. Kang, J. H. Heo, S. H. Im, J. Park, J. Org. Chem 2018, 83, 2640-2646.

[8]X. Yang, X. Xu, G. Zhou, J. Mater. Chem. C 2015, 3, 913-944.

[9]C. Quinton, S. Thiery, O. Jeannin, D. Tondelier, B. Geffroy, E. Jacques, J. Rault-Berthelot, C. Poriel, ACS Appl. Mater. Interfaces 2017, 9, 6194-6206.

[10]L.-S. Cui, Y.-M. Xie, Y.-K. Wang, C. Zhong, Y.-L. Deng, X.-Y. Liu, Z.-Q. Jiang, L.-S. Liao, Adv. Mater. 2015, 27, 4213-4217.

[11]Y. Liu, L.-S. Cui, X.-B. Shi, Q. Li, Z.-Q. Jiang, L.-S. Liao, J. Mater. Chem. C 2014, 2, 8736-8744.

[12]M.-M. Xue, Y.-M. Xie, L.-S. Cui, X.-Y. Liu, X.-D. Yuan, Y.-X. Li, Z.-Q. Jiang, L.-S. Liao, Chem. Eur. J. 2016, 22, 916-924.

[13]Y.-K. Wang, Q. Sun, S.-F. Wu, Y. Yuan, Q. Li, Z.-Q. Jiang, M.-K. Fung, L.-S. Liao, Adv. Funct. Mat. 2016, 26, 7929-7936.

[14]Y.-K. Wang, S.-H. Li, S.-F. Wu, C.-C. Huang, S. Kumar, Z.-Q. Jiang, M.-K. Fung, L.-S. Liao, Adv. Funct. Mater. 2018, 28, 1706228 (1-10).

[15]Z. Yang, Z. Mao, Z. Xie, Y. Zhang, S. Liu, J. Zhao, J. Xu, Z. Chi, M. P. Aldred, Chem. Soc. Rev. 2017, 46, 915-1016.

[16]I. Bulut, P. Chavez, S. Fall, S. Mery, B. Heinrich, J. Rault-Berthelot, C. Poriel, P. Leveque, N. Leclerc, RSC Adv. 2016, 6, 25952-25959.

[17]X.-D. Zhu, X.-J. Ma, Y.-K. Wang, Y. Li, C.-H. Gao, Z.-K. Wang, Z.-Q. Jiang, L.-S. Liao, Adv. Funct. Mater. 2019, 29, 1807094.

[18]W. Yu, J. Zhang, X. Wang, X. Liu, D. Tu, J. Zhang, X. Guo, C. Li, Solar RRL 2018, 2, 1800048.

[19]J. Yi, Y. Wang, Q. Luo, Y. Lin, H. Tan, H. Wang, C.-Q. Ma, Chem. Commun. 2016, 52, 1649-1652.

[20]K. C. Song, R. Singh, J. Lee, D. H. Sin, H. Lee, K. Cho, J. Mater. Chem. C 2016, 4, 10610-10615

[21]X.-F. Wu, W.-F. Fu, Z. Xu, M. Shi, F. Liu, H.-Z. Chen, J.-H. Wan, T. P. Russell, Adv. Funct. Mat. 2015, 25, 5954-5966.

[22]S. Li, W. Liu, M. Shi, J. Mai, T.-K. Lau, J. Wan, X. Lu, C.-Z. Li, H. Chen, Energy Environ. Sci 2016, 9, 604-610.

[23]L. Sicard, C. Quinton, J.-D. Peltier, D. Tondelier, B. Geffroy, U. Biapo, R. Métivier, O. Jeannin, J. Rault-Berthelot, C. Poriel, Chem. Eur. J. 2017, 23, 7719-7723.

[24]K. Ding, Z. Han, Z. Wang, Chem. Asian. J. 2009, 4, 32-41.

[25]X. Cheng, Q. Zhang, J.-H. Xie, L.-X. Wang, Q.-L. Zhou, Angew. Chem. Int. Ed. 2005, 44, 1118-1121.

[26]X. Cheng, J.-H. Xie, S. Li, Q.-L. Zhou, Adv. Synth.Catal. 2006, 348, 1271-1276.

[27]C. Poriel, Y. Ferrand, P. Le Maux, J. Rault-Berthelot, G. Simonneaux, Tetrahedron Lett. 2003, 44, 1759-1761. 
[28]C. Poriel, Y. Ferrand, P. Le Maux, J. Rault-Berthelot, G. Simonneaux, Inorg. Chem. 2004, 43, 5086-5095.

[29]Y. Ferrand, C. Poriel, P. Le Maux, J. Rault-Berthelot, G. Simonneaux, Tetrahedron Asymmetry 2005, 16, 1463-1472.

[30]F. Moreau, N. Audebrand, C. Poriel, V. Moizan-Baslé, J. Ouvry, J. Mater. Chem. 2011, 21, 18715-18722.

[31]J. Jalkh, S. Thiery, J.-F. Bergamini, P. Hapiot, C. Poriel, Y. R. Leroux, J. Phys. Chem. C 2017, 121, 14228-14237.

[32]C. Dalinot, V. Jeux, L. Sanguinet, T. Cauchy, M. Allain, Y. Morille, V. Bonnin, P. Leriche, ACS Omega 2019, 4, 4571-4583.

[33]Y. Wu, J. Zhang, Z. Bo, Org. Lett. 2007, 9, 4435-4438.

[34]Y. Wu, J. Zhang, Z. Fei, Z. Bo, J. Am. Chem. Soc. 2008, 130, 7192-7193.

[35]C. Xu, A. Wakamiya, S. Yamaguchi, J. Am. Chem. Soc. 2005, 127, 1638-1639.

[36]C. Poriel, J. Rault-Berthelot, Acc. Chem. Res. 2018, 51, 1818-1830.

[37]H. Lee, J. Oh, H. Y. Chu, J.-I. Lee, S. H. Kim, Y. S. Yang, G. H. Kim, L.-M. Do, T. Zyung, J. Lee, Y. Park, Tetrahedron 2003, 59, 2773-2779.

[38]C. Poriel, J. Rault-Berthelot, D. Thirion, J. Org. Chem. 2013, 73, 886-898.

[39]D. Thirion, C. Poriel, R. Métivier, J. Rault-Berthelot, F. Barrière, O. Jeannin, Chem. Eur. J. 2011, 17, 10272-10287.

[40]D. Thirion, C. Poriel, F. Barrière, R. Métivier, O. Jeannin, J. Rault-Berthelot, Org. Lett. 2009, 11, 4794-4797.

[41]C. Poriel, F. Barrière, D. Thirion, J. Rault-Berthelot, Chem. Eur. J. 2009, 15, 1330413307.

[42]M. Romain, C. Quinton, D. Tondelier, B. Geffroy, O. Jeannin, J. Rault-Berthelot, C. Poriel, J. Mater. Chem. C 2016, 4, 1692-1703.

[43]S. Bebiche, I. Bouhadda, T. Mohammed-Brahim, N. Coulon, J. F. Bergamini, C. Poriel, E. Jacques, Solid-State Electron. 2017, 130, 49-56.

[44]M. Romain, M. Chevrier, S. Bebiche, T. Mohammed-Brahim, J. Rault-Berthelot, E. Jacques, C. Poriel, J. Mater. Chem. C 2015, 3, 5742-5753.

[45]C. K. Frederickson, B. D. Rose, M. M. Haley, Acc. Chem. Res. 2017, 50, 977-987.

[46]R. G. Clarkson, M. Gomberg, J. Am. Chem. Soc. 1930, 52, 2881-2891.

[47]W. Linert, Y. Fukuda, A. Camard, Coord. Chem. Rev. 2001, 218, 113-152.

[48]M. Sainsbury, Aromatic Chemistry, Oxford University press Inc., New York, 1994.

[49]C. Poriel, R. Métivier, J. Rault-Berthelot, D. Thirion, F. Barrière, O. Jeannin, Chem. Commun. 2011, 47, 11703-11705.

[50]P. Hohenberg, W. Kohn, Phys. Rev. 1964, 136, B864-B871.

[51]R. G. Parr, W. Yang, Density-Functional Theory of Atoms and Molecules, Oxford University Press: Oxford, 1989.

[52]M. J. Frisch, G. W. Trucks, H. B. Schlegel, G. E. Scuseria, M. A. Robb, J. R. Cheeseman, R. Scalmani, G. Barone, B. Mennucci, G. A. Petersson, H. Nakatsuji, M. Caricato, X. Li, H. P. Hratchian, A. F. Izmaylov, J. Bloino, G. Zheng, J. L. Sonnenberg, M. Hada, M. Ehara, K. Toyota, R. Fukuda, J. Hasegawa, M. Ishida, T. Nakajima, Y. Honda, O. Kitao, H. Nakai, T. Vreven, J. A. J. Montgomery, J. E. Peralta, F. Ogliaro, M. Bearpark, J. J. Heyd, E. Brother, K. N. Kudin, V. N. Staroverov, R. Kobayashi, J. Normand, K. Raghavachari, A. Rendell, J. C. Burant, S. S. Iyengar, J. Tomasi, M. Cossi, N. Rega, N. J. Millam, M. Klene, J. E. Knox, J. B. Cross, V. Bakken, C. Adamo, J. Jaramillo, R. Gomperts, R. E. Stratmann, O. C. Yazyev, A. J. Austin, R. Cammi, C. Pomelli, J. W. Ochterski, R. L. Martin, K. Morokuma, V. G. Zakrzewski, G. A. Voth, P. Salvador, J. J. Dannenberg, S. Dapprich, A. D. Daniels, O. Farkas, J. B. 
Foresman, J. V. Ortiz, J. Cioslowski, D. J. Fox, Gaussian 09, Revision B.01, Gaussian, Inc., Wallingford CT 2010

[53]A. D. Becke, Phys. Rev. 1988, 38, 3098-3100.

[54]A. D. Becke, J. Chem. Phys. 1993, 98, 1372-1377.

[55]A. D. Becke, J. Chem. Phys. 1993, 98, 5648-5652.

[56]C. Lee, W. Yang, R. G. Parr, Phys. Rev. B 1988, 37, 785-789.

[57]P. C. Hariharan, J. A. Pople, Chem. Phys. Lett. 1972, 16, 217-219. 